EPiC Series in Computing
Volume 78, 2021, Pages 171-181
Proceedings of the European Univer-
sity Information Systems Conference 2021

\title{
COVID-19 Leap - not only digital but also pedagogical
}

\author{
Suvi Valsta ${ }^{1}$, Tuija Marstio ${ }^{2}$, Virve Pekkarinen ${ }^{3 *}$, and Anssi Mattila \\ ${ }^{1}$ Suvi Valsta Laurea University of Applied Sciences, Finland \\ ${ }^{2}$ Tuija Marstio Laurea University of Applied Sciences, Finland \\ ${ }^{3}$ Virve Pekkarinen Laurea University of Applied Sciences, Finland \\ ${ }^{4}$ Anssi Mattila Laurea University of Applied Sciences, Finland \\ suvi.valsta@laurea.fi, tuija.marstiodlaurea.fi, \\ virve.pekkarinen@laurea.fi, anssi.m.mattila@laurea.fi
}

\begin{abstract}
This article offers an overview of how Laurea, a Finnish university of Applied Sciences navigated the unprecedented situation with the COVID-19 pandemic in 2020. We also share our reflections on the support provided to online teaching and learning through the lens of TPACK, communities of practice (CoP), and learning design models. The empirical part describes how Laurea supported its academic staff in transitioning their teaching online, and at the same time, introduced a new learning management system. A support structure based on channels of peer support played a major role in the success of the transition. In retrospect, we have learnt the importance of routine and psychological safety, especially in these exceptional circumstances. Teachers feel more inclined to try out new technology and methods if there is a safe environment to learn from one's earlier experiences and experiment with new methods.
\end{abstract}

\section{Introduction}

The context of this case study is Laurea University of Applied Sciences, a Finnish Higher Education (HE) Institution providing education in four core study fields: business administration and law; health and welfare; information and communication technologies; and services. Before the COVID-19 pandemic emerged, Laurea had made a strategic decision of adopting a new learning management system (LMS), Canvas, in 2019. An important part of the adoption process was enabling a pedagogical development process parallel to the technical transition to a new LMS. To facilitate pedagogical development, a learning design method was applied when guiding teachers to transition to the new LMS.

\footnotetext{
*https://orcid.org/0000-0003-4863-0821
} 
The emergence of the pandemic challenged teachers further: an already decided adoption of a new learning management system proceeded in addition to transforming traditional face-to-face teaching to an online environment. To both deliver pedagogically suitable online courses and to answer the sudden challenge of the pandemic, multi-faceted support for teachers was needed from the university's support services. In this article, we discuss the theoretical frameworks that guided the process of structuring support, the organisational support roles and the types of support offered to the teachers, and successes and challenges raised in the feedback received from academic and other staff members of the university.

\section{Theoretical aspects for supporting teachers in going digital}

In our digitalized world, there is an ever-growing demand for the use of technology as part of teaching and learning. The COVID-19 pandemic has accentuated this demand. At the same time, it is important to focus on the content and the pedagogical choices, that is, how we teach it. In the following, we discuss the pedagogical and theoretical aspects guiding the digi-pedagogical support at Laurea.

\subsection{Integrating content, pedagogical, and technological knowledge}

TPACK model by Koehler \& Mishra represents well the nature of knowledge required from teachers today. The TPACK model has been successfully applied in higher education studies even though it has not been specifically developed in the context of higher education (e.g., Kushner et. al., 2013; Pekkarinen et al., 2020). The TPACK model draws on the interplay of three primary forms of knowledge: technological, pedagogical, and content knowledge. The model is not about these three forms of knowledge per se, but it emphasises the kinds of knowledge that lie also in the intersections between the three primary forms. (Koehler \& Mishra, 2008, see also Koehler et al., 2014.)

In practice, this means that to create pedagogically meaningful and quality online and hybrid teaching and learning, a teacher needs to be able to integrate not only content and pedagogical knowledge but also technological knowledge. Technological pedagogical content knowledge (TPACK, see Figure 1 below) is wider than the three forms of knowledge individually and it requires an understanding of how different digital tools can be utilized pedagogically meaningfully to support students learning of certain content and achieving the learning outcomes set for learning (Koehler \& Mishra, 2009). At Laurea, the TPACK model offers a framework for providing digi-pedagogical support to the academic staff, that is, facilitating the integration of pedagogical and technological knowledge to content knowledge. 


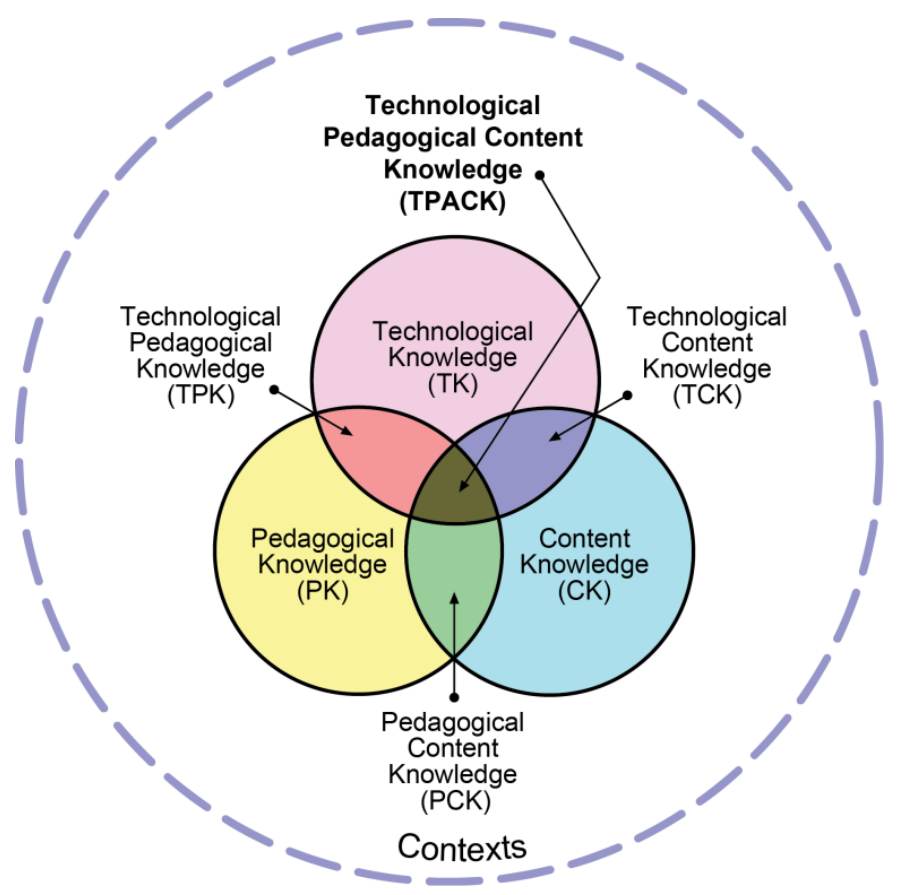

Figure 1: TPACK Model (Koehler \& Mishra, 2008; 2009; Koehler et al., 2014), revised version of the TPACK image. (C) Punya Mishra, 2018. Reproduced with permission.

\subsection{Learning design approach facilitates educational quality}

In addition to technical improvements, the introduction of LMS was seen as an opportunity for a pedagogical renewal of all teaching offered at Laurea, not only through the modern teaching tools integrated into the platform but also through a more student-centred approach. Especially in the case of online courses, there was a need to ensure more student-centred planning of teaching aiming at providing a rich learning experience for the students. It was hence decided that the introduction of the LMS would include both technical and pedagogical training.

For the pedagogical training, a learning design approach was adopted for planning teaching and learning activities. It is a student-centred approach to planning learning tasks or activities, enacting the collaborative inquiry that enables teachers to make their intuitive processes both visible and shareable (Ghislandi \& Raffaghelli, 2015). Learning design shifts away thinking about what the teacher does to focus on what learning activities the students need to experience to achieve the learning outcome for the specific module or course.

As a concrete method for the pedagogical training, the $\mathrm{ABC}$ Learning Design (LD) was adopted as it meets very well the concept of learning design and can be carried out in a short amount of time. It is based on the conversational framework designed by Diana Laurillard which describes six main types of learning (Laurillard, 1993). The ABC LD method builds on these types of learning and integrates them into the course design. It comprises a 90-to-120-minute workshop during which teacher teams, i.e., lecturers of the same discipline, design a visual manuscript for a course. The method was originally designed to be implemented face-to-face but, after closing down the campuses in March 2020, it was adapted to an online version at Laurea using Microsoft Word, Padlet, and Miro as alternative platforms for the course storyboards. In addition to quick workshops, the outcome of the $\mathrm{ABC}$ session provides a 
highly usable, apt base for building courses in the new LMS because student's learning path is described in a detailed manner in the outcome.

\subsection{Communities of Practice promote collaborative sharing of teaching knowledge}

The $\mathrm{ABC}$ learning design workshops offer teacher teams an opportunity for pedagogical content knowledge development and sharing their teaching knowledge. Teaching knowledge is tacit knowledge that cannot be reduced to a set of written guidelines or captured on video instructions. Thus, the learning design approach to course planning for teaching teams via workshops has enabled the birth of Communities of Practice (CoPs) at Laurea as they offer a powerful channel for building, testing, and sharing pedagogic ideas.

The concept of CoPs was introduced already in the ' 90 s by Jean Lave and Etienne Wenger when they referred to a group of individuals who share a common interest and a desire to learn from and contribute to the community with their knowledge and experiences (Lave \& Wenger, 1991). Communities of Practice can be characterized by three distinct traits: domain, practice, and community. The domain refers to an area of shared interest. Practice is a shared body of knowledge, experiences, and techniques. Community relates to a group of individuals who share a passion for something they do. (Wenger, 1998.) Figure 2 below describes how a CoP is a space between loose social networks and focused work teams. It serves as an essential place to learn and develop new ideas with peers.

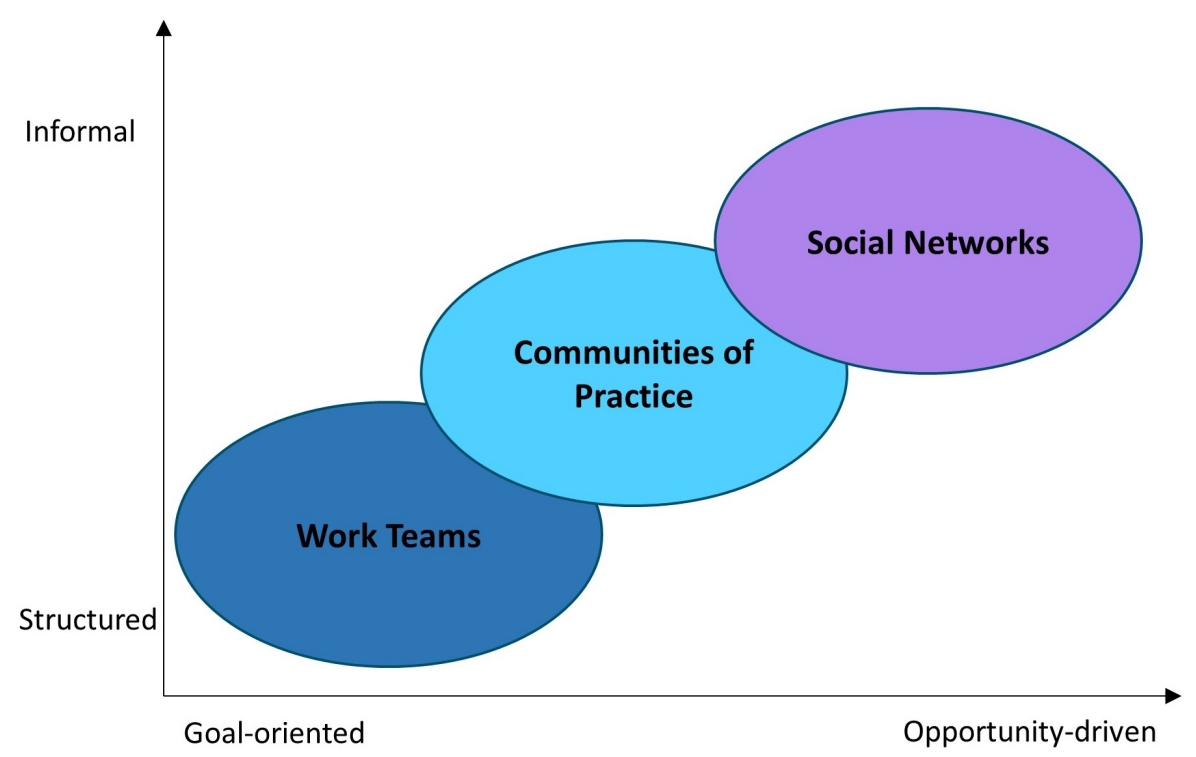

Figure 2: Communities of Practice (based on Jarche, H. 2016)

The learning design approach to course planning has enabled the emergence of Communities of Practice (CoPs) at Laurea as it enables an opportunity for building, testing, and sharing pedagogic ideas among teachers. Due to the COVID-19 pandemic, the collaboration between teachers has been mainly virtual, using online tools. In practice, the sharing of practices consists of discussion boards and chats on social media. In addition, the CoPs have been operating through the learning design workshops, using the LMS as a platform. 


\section{Digi-pedagogical support actions for facilitating the creation of hybrid and online teaching and learning}

To deliver online teaching and build new courses in Laurea's new LMS, pedagogical and technical support for teachers was needed from the university's support services. In this section, we will introduce the core actors involved in providing digi-pedagogical support to Laurea teachers, what types of support are being provided and the channels through which they are delivered to the teachers.

\subsection{Core actors providing digi-pedagogical support}

The core actors in supporting teachers in the three TPACK knowledge areas (see Figure 1) are the digi-pedagogical unit dCELL (The Digital Cell of Laurea), Laurea IT department, and academic coordinators for each degree programme. They form the formal work teams in the CoP framework. The work teams are characterised by the sharing of complex knowledge and are usually driven by deadlines. There are often strong social ties between the members of these teams, and they have complementary skills (Zárraga Oberty \& de Saá-Pérez, 2006).

dCELL is the central actor for providing support for digitalising teaching and learning at Laurea. It comprises specialists in digital pedagogy and digital learning environments and tools. dCELL is responsible for offering different forms and types of digi-pedagogical support for the teachers to facilitate the creation of both hybrid and online teaching and learning environments. The IT department, for its part, offers infrastructure and hardware-level support to the whole university. The degree programme coordinators are responsible for academic course content and the overall course development.

Figure 3 below presents how the CoPs are aligned with formal focused work teams and the wider social networks inside and outside Laurea.

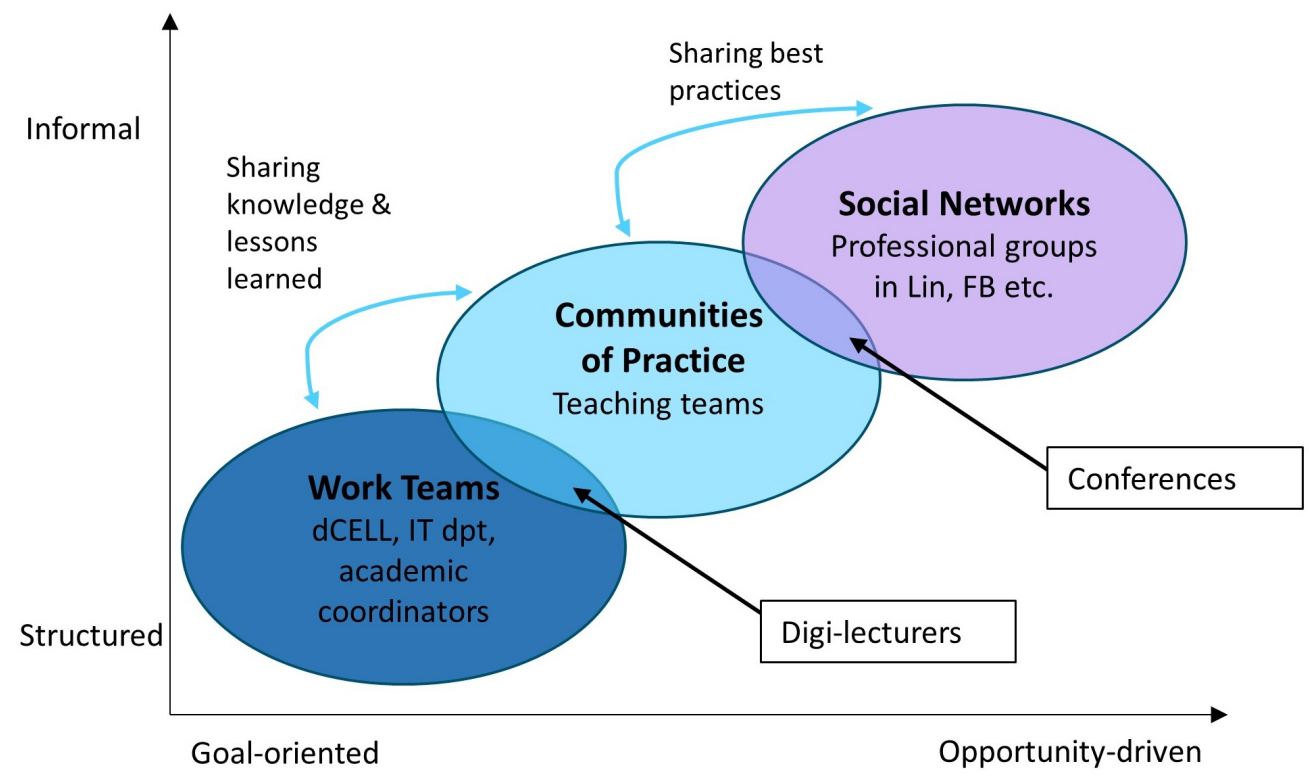

Figure 3: Communities of Practice at Laurea (by Tuija Marstio, based on Jarche, H. 2016) 
At the intersection of formal work teams and CoPs, there are 10 digi-pedagogical lecturers. They are lecturers representing different disciplines and campuses of Laurea and, parallel to their teaching work, they spend $20-50 \%$ of their working hours supporting and training their peers in digi-pedagogical issues. The digi-lecturers are a part of the dCELL unit and the dCELL provides the structure for the digi-lecturer activity. This way, dCELL is strongly connected to the everyday work in the different campuses. The digi-lecturers act as "double agents" by bringing the message from the campuses and disciplines to dCELL and disseminating dCELL's message to the campuses. This ability to be aware of the organizational situation is crucial to meet the challenges of large transition and implementation projects, such as the introduction and adoption of a new LMS. This ability to sense the organisation's state of affairs is critical in responding to the challenges of large transition and implementation projects, such as the adoption of the new LMS. The digi-lecturers also play a focal role in implementing Laurea's strategy, which states that the volume and accessibility of high-quality, open, online education should be increased. Digi-lecturers have been actively involved in creating and updating online courses, and they have been highly effective in disseminating the quality criteria for online course implementation among the teachers and adopting the criteria to use in courses built on the new LMS. This can be assumed to have contributed to the overall quality of online teaching as well.

In addition to the digi-lecturers, there are numerous small Communities of Practice that are formed by instructional team clusters that are organised around course design. The CoPs also provide learning opportunities beyond the campuses. The work of these CoPs is facilitated by dCELL and the digilecturers. The composition of these teams may vary and there are mixed, both formal and informal, ties between the team members.

For any organisation based on knowledge work, it is important to be open to new ideas that come from loose social networks within and outside the organisation. While communities of practice are characterized by shared identity around a topic representing a collective intention, members of Social Networks are connected by friendship, work relationship, hobby, or other shared interest (WengerTrayner, 2011). They offer learning opportunities beyond the boundaries of an organization. In the CoP framework, social networks are characterized by the diversity of ideas and opinions (Jarche, 2018). The social ties between the various actors may be weak but, with the help of technology available, those weak ties do not impede sharing of information and best practices. Social media groups (for example, on LinkedIn and Facebook) for teachers are the most prominent examples of social networks in this context. In addition, conferences, such as those targeted to online educators, are an example of the intersection of social networks and CoPs.

\subsection{Support through multiple channels}

It is widely accepted that being and developing as a teacher requires reflection (e.g., Brookfield, 1995; McAlpine et al., 1999; Schön, 1983). In addition, social reflection, that is, having discussions and sharing experiences and emotions with colleagues, is important in how teachers experience their identities, themselves as teachers, and their pedagogical competency (Pekkarinen et al., 2020; Pyörälä et al., 2015; Roxå \& Mårtensson, 2009; Uitto et al., 2015). The need for reflection and social sharing has been taken into consideration while planning and providing support for teachers, as a major part of the digi-pedagogical support at Laurea is built on peer and collegial support (see Table 1).

For example, teachers were offered a virtual Microsoft Teams space called "Support for online learning" with different thematic channels to have discussions with each other and with dCELL's digipedagogical specialists. In this virtual space, teachers could also share their experiences and emotions related to the COVID-19 situation, reforming their teaching, and the pedagogical renewal that had already started before the COVID-19 pandemic emerged. In addition to the above, teachers could use 
this space to build a network of peers with similar interests and who they can approach in informal settings online and offline.

Besides the structures based on peer support, the support offered to teachers included frequent online events, such as support clinics organised daily at the start of the pandemic and on Tue and Thu mornings weekly after that. These events aimed to be low-threshold easy-to-join events that teachers can join without prior registration. In addition to the weekly support clinics, Laurea also organised pedagogical and thematic workshops focusing in-depth on digi-pedagogical topics, such as ABC Learning Design, application of pedagogical models online, selection and use of suitable digital tools, facilitating online collaboration, feedback, and assessment, to mention a few. These weekly training sessions and specialized workshops offered another channel for teachers to connect, which can be especially crucial for someone only recently joining Laurea as a teacher.

\begin{tabular}{lll}
\hline Type of support & Who? & What? \\
\hline Technical training & $\begin{array}{l}\text { dCELL specialists, teacher } \\
\text { volunteers specialising in } \\
\text { specific online tools } \\
\text { dCELL specialists, digi- } \\
\text { lecturers }\end{array}$ & $\begin{array}{l}\text { Support clinics, thematic } \\
\text { workshops }\end{array}$ \\
Pedagogical & $\begin{array}{l}\text { Pedagogical workshops, } \\
\text { thematic training } \\
\text { Migi-lecturers, peers in } \\
\text { Microsoft Teams support } \\
\text { channels }\end{array}$ & $\begin{array}{l}\text { Collegial support at the } \\
\text { campuses, thematic Microsoft } \\
\text { Teams channels for discussion } \\
\text { and Q\&A }\end{array}$ \\
\hline
\end{tabular}

Table 1: Overview of the types of support offered to teachers at Laurea in 2020\&2021

\section{The successes and challenges of digi-pedagogical support services}

To evaluate the success of digi-pedagogical support and services offered at Laurea, we collected preliminary feedback from teachers via a small qualitative survey in December $2020(\mathrm{~N}=8)$. The teachers answered questions about which of the services they used and found to benefit them the most. A new more in-depth survey concerning all university-level support services was conducted in Jan-Feb 2021. The respondents were both academic and non-academic staff members $(\mathrm{N}=92)$. The survey also included a qualitative part gathering feedback about dCELL's digi-pedagogical support and services. The data from both surveys were analysed, and the findings are discussed here in unison.

Overall, the various support types, such as the technical support clinics and pedagogical workshops, were experienced as useful by the respondents. The Microsoft Teams support channels and extensive support materials were also reported to be helpful in teacher's daily work. The respondents experienced that their questions in the Teams channels were answered very actively and often during the same day by peers and dCELL specialists. The weekly training sessions on fixed weekdays provided the respondents a routine as they always knew when and how to get support. In addition to the above, having a network of teacher peers allowed conducting ad hoc testing of new solutions in online environments in an agile manner and, if successful, even adopting that into an ongoing course.

The availability of peer support from digi-lecturers and other peers and the weekly training sessions also provided the teachers with psychological safety. The feeling of psychological safety also contributed to experimenting with new teaching methods and digital solutions and creatively finding solutions most suitable to one's style of teaching. 
In addition to the feedback indicating that the service structure of Laurea supports the effective delivery of digi-pedagogical support, there were also some challenges raised in the survey data that were connected closely to the organisation structure and division of responsibilities in the organisation. University support services are often divided between different units responsible for IT, pedagogical and administrative services, and Laurea is no exception to this model. Based on the survey data collected, it was apparent that some of the respondents found navigating between different service providers in the university to be difficult and did not always know who to contact or what services were available. This resulted in the teachers directing their questions to individual digi-pedagogical specialists or digi-lecturers instead of contacting the official support channels or contacting the wrong service functions. This, in turn, may have led to a delay in responding to the support request. We do not mean to say that teachers should not contact digi-lecturers, as the whole concept of digi-lecturers is based on the idea of a teacher being able to contact peers and receive individual support. However, the intended support structure and its contact channels should be communicated clearly to the organisation's members. Otherwise, it might result in an individual becoming burdened by the requests for help from their peers.

As the support structure has now been in place for approximately one year, it may be too early to evaluate its impact at large on Laurea's operations and key performance indicators. However, the number of attained degrees and accumulated study credits for Laurea students in 2020 has not dropped even amidst the pandemic. These metrics indicate that the support structure described in section 3 indeed supports both the teachers and, through their teaching and conscious digi-pedagogical choices, the students as well.

\section{Conclusions and observations}

The COVID-19 pandemic has encouraged teachers to collaborate more and to share their knowledge. Technology enables the collaborative sharing of pedagogical patterns and best practices and the different methods of learning design offer a great platform for developing online education. However, if a teacher tries to replicate the traditional face-to-face style of teaching online, it is likely that the quality of teaching suffers greatly. Ideally, all courses should be tailored specifically to the learning context and target group of students.

The width of the support structure combining peer support and digi-pedagogical expertise, that is, having both digi-pedagogical specialists in dCELL and digi-lecturers supporting academic staff from their role, allows Laurea to give more personalised support to teachers - not merely linking them instructions and other support materials, but also providing them with digi-pedagogical help and guidance in designing their online courses.

Additionally, the Communities of Practice have become an integral part of Laurea's organisation. Through them, teachers can share and build on each other's work to enrich their professional and pedagogical knowledge. By providing rewarding challenges as well as a structure and platform for these communities to act it is possible to sustain them. However, it also requires resources to be allocated to those who form the core of these communities. It is also recommendable to keep the nature of the communities informal.

The training sessions described above continue currently at Laurea, with a stable attendance rate from both frequent visitors and newcomers. The digital tools and online spaces also enable peer support and social reflection. Teachers have been reporting that they feel empowered as they can easily ask for help from peers and colleagues and share their own teaching experiences simultaneously. However, our experience shows that the available support channels need to be communicated clearly. 


\section{References}

Brookfield, S. (1995). Becoming a critically reflective teacher. San Francisco, CA: Jossey-Bass. Ghislandi, P. \& Raffaghelli, J. (2015). Forward-oriented designing for learning as a means to achieve educational quality. British Journal of Educational Technology. 46(2).

Jarche, H. (2012). Boundaries are for learning. Retrieved May 21 2021, from: https://warmoes.blogs.com/km_select/2012/05/boundaries-are-for-learning-harold-jarche.html

Jarche, H. (2016). Implementing network learning. Retrieved May 21 2021, from: https://jarche.com/2016/08/implementing-network-learning/

Jarche, H. (2018). Finding community. Retrieved May 21 2021, from: https://jarche.com/2018/11/finding-community/

Koehler, M. J. \& Mishra, P. (2008). Introducing TPACK. In AACTE Committee on Innovation \& Technology (Ed.), Handbook of technological pedagogical content knowledge for educators, 3-29. New York, NY: Routledge.

Koehler, M. J. \& Mishra, P. (2009). What is technological pedagogical content knowledge? Contemporary Issues in Technology and Teacher Education, 9(1), 60-70.

Koehler, M. J., Mishra, P., Kereluik, K., Shin, T. S., \& Graham, C. R. (2014). The technological pedagogical content knowledge framework. In J. Spector, M. Merrill, J. Elen, \& M. Bishop (Eds.), Handbook of research on educational communications and technology (pp. 101-111). New York, NY: Springer. doi:10.1007/978-1-4614-3185-5_9.

Kushner Benson, S. N., \& Ward, C. L. (2013). Teaching with technology: Using TPACK to understand teaching expertise in online higher education. Journal of Educational Computing Research, 48(2), 153-172. doi:10.2190/EC.48.2.c.

Laurillard, D. M. (1993). Rethinking University Teaching: A Framework for the Effective Use of Educational Technology. London: Routledge.

Lave, J. \& Wenger, E. (1991). Situated Learning: Legitimate Peripheral Participation. Cambridge: Cambridge University Press.

McAlpine, L., Weston, C., Beauchamp, C., Wiseman, C., \& Beauchamp, J. (1999). Building a metacognitive model of reflection. Higher Education, 37, 105-131. doi:10.1023/A:1003548425626.

Mishra, P. (2018). Revised version of TPACK image. Retrieved 17 Sep 2021, from: https://punyamishra.com/2018/09/10/the-tpack-diagram-gets-an-upgrade/

Pekkarinen V., Hirsto L., \& Nevgi A. (2020). Ideal vs. experienced: University teachers' perceptions of a good university teacher and their experienced pedagogical competency. International Journal of Teaching and Learning in Higher Education, 32(1), 13-30.

Pyörälä, E., Hirsto, L., Toom, A., Myyry, L., \& Lindblom-Ylänne, S. (2015). Significant networks and meaningful conversations observed in the firstround applicants for the teachers' academy at a research-intensive university. International Journal for Academic Development, 20(2), 150-162. doi:10.1080/1360144X.2015.1029484.

Roxå, T. \& Mårtensson, K. (2009). Significant conversations and significant networks - exploring the backstage of the teaching arena. Studies in Higher Education, 34(5), 547-559. doi:10.1080/03075070802597200.

Schön, D. (1983). The reflective practitioner: How professionals think in action. New York, NY: Basic Books.

Uitto, M., Kaunisto, S.-L., Syrjälä, L., \& Estola, E. (2015). Silenced truths: Relational and emotional dimensions of a beginning teacher's identity as part of the micropolitical context of school. Scandinavian Journal of Educational Research, 59(2), 162-176.

Wenger, E. (1998). Communities of Practice: Learning, Meaning and Identity. Cambridge University Press.

Wenger-Trayner, E. \& Wenger-Trayner, B. (2011). Communities versus networks? Retrieved May 21 2021, from: https://wenger-trayner.com/resources/communities-versus-networks/ 
Zarraga Oberty, C. \& de Saá-Pérez, P. (2006). Work teams to favor knowledge management: Towards Communities of Practice. European Business Review 18(1):60-76. doi: $10.1108 / 09555340610639851$

\section{Author biographies}

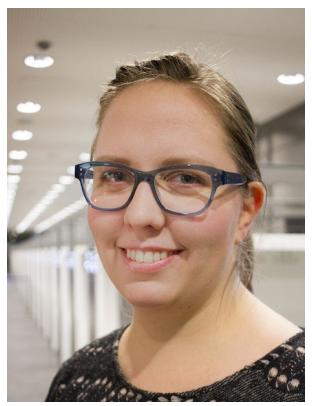

Suvi Valsta is a MOOC Coordinator at dCELL at the Laurea University of Applied Sciences. She holds an MA degree from the University of Helsinki and is currently pursuing an MBA in Service Innovation and Design at Laurea. She has a work background in teaching, IT support, and IT management, and was the project manager for the EUNIS2020 Virtual Congress.

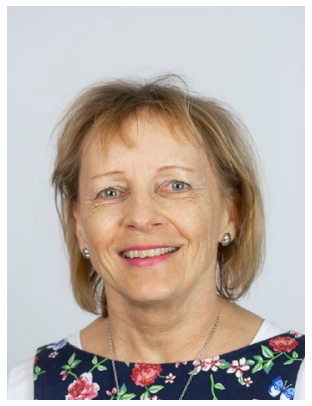

Tuija Marstio (MSc, Econ) works as an Expert in Digital Pedagogy and Senior Lecturer at Laurea University of Applied Sciences. She has been working in the field of education and training for more than 30 years and has gained a strong insight into digital pedagogy, online education, digital marketing, entrepreneurial training, and international business operations. At Laurea, she contributes to the development of online learning through staff training and managing various digital learning initiatives. She has also an extensive background in international project management and has managed several projects in the fields of education and business-related ICT in Latin America, Asia, and Africa. She is fluent in Spanish. Ms. Marstio has published several articles on online learning and learning design.



Mrs. Virve Pekkarinen is an Expert in Digital Pedagogy and a teacher in charge of the Master level RDI path studies at Laurea University of Applied Sciences. She holds an MA degree from the University of Helsinki in Adult Education, and she is an officially qualified teacher. Currently, she is pursuing her $\mathrm{PhD}$ in Education, and also MBA in Leading Business Transformation. She has extensive work experience in the higher education field in teaching, teacher training, digital pedagogy, university pedagogy, and competency development. Mrs. Pekkarinen has published internationally in the field of university pedagogy e.g., in the Scandinavian Journal of Educational Research and the International Journal of Teaching and Learning in Higher Education. In addition, Mrs. Pekkarinen has acted as a peer reviewer in EAPRIL 2016 conference, and she was a member of a team that won the Best Research and Practice Project Award at the EAPRIL 2018 conference. 


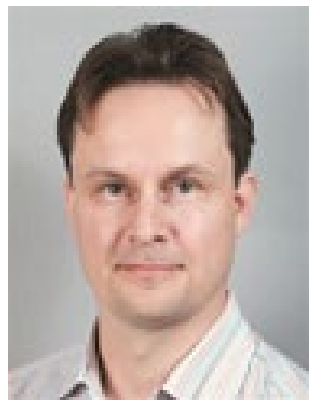

Dr. Anssi Mattila is a Principal Lecturer at the Laurea University of Applied Sciences and an Adjunct Assistant Professor at the Embry-Riddle Aeronautical University (U.S.). Before his current position, he specialized in the management of information security and technical information security. He has served the European Commission as an Expert Evaluator and his current research interests include improving the quality and efficiency of online learning environments, enhancing creativity in designing online courses, and advancing online teaching skills and competencies. His publication activities include journals such as International Journal of Financial Services Management; Problems and Perspectives in Management; Journal of Education, Psychology and Social Science; International Journal of Computing and Business Research; and International Journal of Enterprise Computing and Business Systems. 